\title{
GenomEUtwin: A European Community Framework 5 Functional Genomics Special Initiative
}

\author{
O. Quintana Trias \\ Director, Health Research, Directorate General for Research, European Commission, Brussels
}

The GenomEUtwin project ("Genome-wide analyses of European twin and population cohorts to identify genes predisposing to common diseases") was selected by the European Commission in October 2002 as one of three "QoL integrated projects" under a special initiative in the area of functional genomics relating to human health. The projects are funded by the Quality of Life Programme of the European Community's 5th Framework Programme for research (1998-2002). ${ }^{1}$ GenomEUtwin is supported by a grant of $€ 13.7$ million from the European Community.

A QoL integrated project contains three components - research, networking, and training and mobility within a common integrated management structure. Under the research component, the project is expected to perform ground-breaking research. Under the networking component, the project should create synergy with and between national research efforts in the field. And under the training and mobility component, the project should provide opportunities to train young researchers at Europe's top research centres in the field. QoL integrated projects have also been designed to give a measure of autonomy to the research consortium. The evolution of a detailed programme of activity is determined by mutual agreement between the consortium, a scientific advisory board and the Commission as the project proceeds.

GenomEUtwin has been running for a year and has already established a network of the major European twin cohorts, and top European expertise in epidemiology, genetics and biostatistics. Thus, GenomEUtwin represents one of the largest research projects in molecular epidemiology in the world and the focus on the genetics of twins adds special scientific value - the project is one illustration of the great strengths of Europe in this field. The research infrastructure that is being built up and the novel molecular and statistical methods to be developed in GenomEUtwin will be a valuable resource for future biomedical research programmes in Europe. The results of the research will be important not only for improved understanding of the genetic background of common diseases but also for the development of novel treatment strategies, in partnership with European industry, and in European healthcare and prevention programs. The project will also contribute to the future of molecular epidemiology by providing training opportunities in for young researchers and for more advanced clinicians and scientists. The project also pays attention to ethical, legal and social issues inherent in large scale, trans-European studies in population genetics.

In scale and ambition, therefore, GenomEUtwin, along with the two other large genomics for health projects in FP5, represent pilot projects for the new integrated projects of the European Community's 6th Framework Programme (FP6; 2002-2006) ${ }^{2}$. This particular project serves not only as a model for large scale project management and the way that it helps structure the field of molecular epidemiology in Europe, but also because of the importance attached to population genetics and epidemiology in Thematic Priority 1 of FP6, "Life sciences, genomics and biotechnology for health". In this part of FP6, both fundamental and translational research will be supported, with an emphasis on integrated, multidisciplinary, and coordinated efforts that address the present fragmentation of European research in functional genomics; there is often considerable overlap between national research efforts. Research in the field will also help to strengthen the competitiveness of the European biotechnology industry. An indicative budget of $€ 2.255$ million has been allocated to thematic priority 1 for the period 2002-2006.

The GenomEUtwin project exemplifies the strength and breadth of the field of twin research in Europe and points to the potential benefits of "post-genomic" research for the health of European citizens. I welcome this special edition of Twin Research as an important contribution to disseminating the first results of the project to a wide scientific audience.

\section{Endnotes}

1 The projects are GenomEUtwin, SPINE, EUMORPHIA with a total EU contribution of $€ 39.4$ million see http://www.cordis.lu/lifescihealth/genomics/ fp5-projects_geno.htm.

2 See the calls for proposals in LifeSciHealth at http:// www.cordis.lu/lifescihealth/home.html 